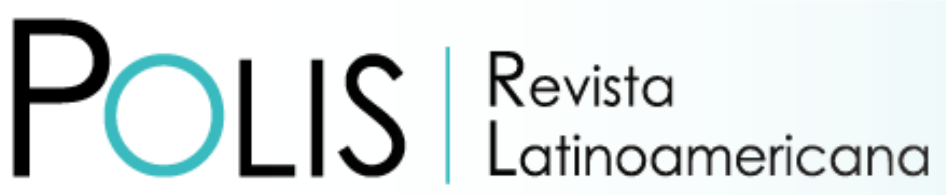

V20 | N60 | 2021

DOI: $10.32735 /$ S0718-6568/2021-N60-1505

\title{
Violência, guerra às drogas e racismo de estado no Brasil
}

\author{
Rodrigo Alvarenga \\ Pontifícia Universidade Católica do Paraná, Curitiba, Brasil. \\ Email: alvarenga.rodrigo@pucpr.br \\ Caroline Filla Rosaneli \\ Pontifícia Universidade Católica do Paraná, Curitiba, Brasil. \\ Email: caroline.rosaneli@gmail.com \\ Ramon Andrade Ferreira \\ Centro social Marista Propulsão, Curitiba, Brasil. \\ Email: ferreiraramon@gmail.com \\ Cezar Bueno de Lima \\ Pontifícia Universidade Católica do Paraná, Curitiba, Brasil. \\ Email: czarbueno@gmail.com
}

Recibido: 09.05.2020 | Aceptado: 23.10.2020

\begin{abstract}
Resumo: A política de 'guerra às drogas' gera uma situação de violência generalizada na sociedade brasileira, especialmente para aqueles que se encontram em condição de maior vulnerabilidade econômica, social e étnico-racial. Tendo por base os dados dos últimos anos sobre homicídios, mortes decorrentes de intervenção policial e vitimização policial, crimes por tráfico e encarceramento, o artigo tem como objetivo analisar a relação entre a violência derivada da política de drogas existente no Brasil e o racismo. Considerados numa perspectiva biopolítica, os dados indicam que a política de 'guerra às drogas' opera pela construção da noção de indivíduo perigoso e pela seletividade penal e letal de pessoas negras, revelando a natureza racista do próprio Estado, não apenas ao estabelecer quem deve viver e quem deve morrer, mas produzindo a morte, promovendo a necropolítica.
\end{abstract}

Palavras-chave: Drogas; racismo; violência; direitos humanos.

\section{Violencia, guerra contra las drogas y racismo estatal en Brasil}

Resumen: La política de "guerra contra las drogas" genera una situación de violencia generalizada en la sociedad brasileña, especialmente para quienes se encuentran en una condición de mayor vulnerabilidad económica, social y étnico-racial. A partir de datos de los últimos años sobre homicidios, muertes por intervención policial y victimización policial, delitos por trata y encarcelamiento, el artículo tiene como objetivo analizar la relación entre la violencia derivada de la política de drogas en Brasil y el racismo. Considerada desde una perspectiva biopolítica, los datos indican que la política de 'guerra contra las drogas' 
opera construyendo la noción de un individuo peligroso y por la selectividad criminal y letal de los negros, revelando la naturaleza racista del propio Estado, no solo al establecer quién debe vivir y quién debe morir, sino que, además produciendo la muerte, promoviendo la necropolítica.

Palabras-clave: Drogas; racismo; violencia; derechos humanos.

\title{
Violence, Drug War and State Racism in Brazil
}

\begin{abstract}
The 'war on drugs' policy generates a situation of widespread violence in Brazilian society, especially for those who are in a condition of greater economic, social and ethno-racial vulnerability. Based on data from recent years on homicides, deaths resulting from police intervention and police victimization, crimes by trafficking and incarceration, the article aims to analyze the relationship between violence derived from drug policy in Brazil and racism. Considered from a biopolitical perspective, the data indicate that the "war on drugs' policy operates by building the notion of a dangerous individual and by the criminal and lethal selectivity of black people, revealing the racist nature of the state itself, not only in establishing who should live and who should die, but also in producing death thus promoting necropolitics.
\end{abstract}

Keywords: Drugs; racism; violence; human rights.

\section{Como citar este artículo:}

Alvarenga, R., Filla Rosaneli, C., Andrade Ferreira, A y Bueno de Lima, C. (2021). Violência, guerra às drogas e racismo de estado no Brasil. Polis Revista Latinoamericana, 20 (60), 130148. doi: http://dx.doi.org/10.32735/S0718-6568/2021-N60-1505

\section{Introdução}

Os problemas relacionados às substâncias psicoativas ilícitas têm sido objeto de discussões políticas ao redor do mundo, com destaque para Uruguai, Portugal e mais recentemente México e Canadá, países que têm enfrentado o senso comum na discussão sobre o proibicionismo e repensado as políticas belicosas de enfrentamento do mercado ilegal de drogas, a partir do entendimento do problema enquanto uma questão de saúde e não apenas de segurança pública. No território brasileiro, contudo, com histórico escravocrata e uma população fortemente influenciada pelo mito da democracia racial, o problema das drogas acaba por tomar proporções que demandam uma melhor investigação.

O binômio racismo-pobreza, que se configura como um marco estrutural que caracteriza e orienta seletivamente os processos de criminalização, prisão e homicídios no país, aparece de forma regular e dramática nas estatísticas oficiais encarregadas de produzir e divulgar os dados sobre a violência, revelando os perfis dos sujeitos capturados pelo aparato de repressão e controle do Estado. Percebe-se, em regra, que os jovens e adultos negros e oriundos das classes sociais subalternas constituem, por assim dizer, o núcleo preferencial da ação cotidiana do sistema de justiça criminal e repressão policial. Desse modo, levanta-se o 
seguinte questionamento: seria possível afirmar que a política de 'guerra às drogas' é utilizada como parte de uma estratégia institucional de manutenção da desigualdade e da exclusão, fundamentada em uma lógica racista pelas quais se justificam as práticas de extermínio?

O presente artigo, a partir de uma perspectiva interdisciplinar, tem como objetivo analisar de que forma a política de drogas no Brasil pode estar associada a expressões do racismo de Estado, tendo por base os dados oficiais sobre a violência e encarceramento divulgados pelo Fórum Brasileiro de Segurança Pública, pelo Instituto de Pesquisa Estatística Aplicada (IPEA), pelo Levantamento Nacional de Informações Penitenciárias (Infopen) e pelo Sistema Nacional de Atendimento Socioeducativo (Sinase). Buscou-se referenciar os dados relativos ao número de homicídios, às ocorrências de crimes de tráfico de entorpecentes, posse e uso de entorpecentes, mortes decorrentes de intervenção policial e vitimização policial, considerando as informações referentes à identificação racial das vítimas.

Para a análise dos dados foram consideradas as perspectivas filosóficas da Biopolítica, de Michel Foucault $(1988,1996,1999)$, especialmente o conceito de racismo de estado e seus desdobramentos na concepção de Necropolítica, de Achille Mbembe (2016). Além disso, para desenvolver uma análise sociológica dessa relação entre política de drogas e racismo, conforme sugerida pelos dados da violência policial e do encarceramento no Brasil, foram utilizados autores como Hart (2014, 2015), Passeti (2003), Zaconne (2007), Wacquant (2006), entre outros. Inicialmente se procurou delimitar conceitualmente a biopolítica e o conceito de racismo de Estado, para em seguida caracterizar os aspectos sociais relacionados à violência no Brasil, bem como o contexto da produção dos dados apresentados. Após análise dos dados, buscou-se demonstrar a relação direta entre o racismo, violência e encarceramento da população negra com a política de guerra às drogas.

Ficou evidente que as maiores vítimas de mortes decorrentes de intervenção policial no Brasil são pessoas negras, além disso, os policiais que mais morrem vítimas de assassinato também são negros. Desse modo, é possível afirmar que a criminalização e a política de 'guerra às drogas' têm consequências que não são meros efeitos colaterais de um enfrentamento em nome da paz e da justiça, mas pode ser considerado uma prática biopolítica racista do próprio Estado, conforme o conceito estabelecido por Michel Foucault. Mais do que isso, percebe-se que a letalidade policial contra jovens negros, assim como a morte de policiais, também na sua maioria negros, estão para além de simplesmente expor à morte ou deixar morrer, conforme a perspectiva biopolítica, mas consiste numa pratica de extermínio direta no sentido necropolítico estabelecido por Achille Mbembe. 


\section{Biopolítica e Racismo de Estado}

A biopolítica é considerada uma tecnologia de governo segundo a qual a própria vida humana passa a ser inserida na ótica da gestão governamental, transformando as relações de poder de natureza hierárquica verticalizada, entre o soberano e a sociedade civil, numa perspectiva mais horizontal, na qual o poder não é passível de ser localizado no micro espaço ou em uma pessoa específica (Quintana, 2012). A política passa a não incidir apenas sobre o espaço público, mas invade a esfera privada da existência e avança para a produção de subjetividades submissas às estruturas hierárquicas de poder, com base em padrões de normatividade inspirados em ideais utópicos de humanidade, desenvolvimento econômico e progresso material.

Modifica-se a política da relação entre o soberano e a sociedade, pela alteração do poder de punir e de impor a morte como forma de governar. "A velha potência da morte que se simbolizava o poder soberano é agora, cuidadosamente, recoberta pela administração dos corpos e pela gestão calculista da vida" (Foucault, 1988, p. 131). Surge a era do biopoder, não apenas operando por meio das instituições disciplinares, tais como escolas, presídios, asilos e hospitais psiquiátricos, mas utilizando-se também do conhecimento produzido sobre o conjunto da população, por meio da estatística, da demografia, da criminologia e da natalidade, por exemplo.

Nessa perspectiva, o critério de civilização, e consequentemente de civilizado, fez com que as violências, sobretudo físicas em um primeiro momento, fossem consideradas abomináveis, tratadas como costumes de bárbaros e selvagens. Neste sentido, 0 ideal de evolução social, culturas e nacionalidades 'melhores' que outras é calculado através dos fenômenos de violência, uma vez que a 'sociedade evoluída' remonta ao ideal de sociabilidades pacíficas. Um mito cultural que em sua centralidade baseia-se no racismo, evidenciando por meio de dispositivos de poder linguístico de sociedades superiores a outras, permeando o critério da razão desenvolvimentista e a elucidação de violências institucionais e simbólicas (Foucault, 1996).

Logo no início do século XX, este desenvolvimentismo desenfreado e o exacerbado racismo eurocêntrico culminou na explosão de práticas genocidas, no próprio critério civilizacional do ocidente, com conflitos devastadores e práticas contra os povos considerados inferiores. Neste contexto, Estados totalitários difundiram suas técnicas almejando uma sociedade perfeita, findada nos moldes biológicos de sujeitos alocados em patamares supostamente elevados na escala evolutiva das sociedades. Conforme identificado por Foucault (1988), a biopolítica foi a estratégia empregada por estes Estados, identificando, classificando e dominando os corpos individuais para transformá-los em corpos sociais administrados conforme os objetivos do governo. Segundo o filósofo francês:

[...] As disciplinas do corpo e as regulamentações da população constituem os dois polos em torno dos quais se desenvolvem a organização do poder sobre a vida. A instalação econômica e biológica, individualizante e especificamente, voltada para os desempenhos do corpo e encarando os processos da vida-caracteriza um poder cuja função mais elevada já não é mais matar, mas investir sobre a vida, de cima a baixo [...] Abre-se, assim, a era de um 'bio-poder' (Foucault, 1988, p. 152). 
Esta formulação foucaultiana explica as intenções ou as causas iniciais do processo de transformação do Estado em disciplinador dos sujeitos sociais, objetivando a incidência de uma sociedade "evoluída". Por meio de movimentos biológicos, controlando a natalidade, mortalidade e as estatísticas sobre saúde e doença, este biopoder possibilitou domesticar a sociedade através de políticas de controle, com seus diversos dispositivos, entre os quais se destaca o racismo de Estado. Se por um lado a sociedade investe na vida de valor e a produz conforme o padrão normativo vigente pela produção da subjetividade, por outro, como condição de possibilidade, é preciso existir o seu oposto, a raça ruim, aquela que deverá desaparecer conforme se aperfeiçoa a humanidade.

Considerando a guerra das raças, que caracterizou historicamente parte dos conflitos humanos, a vitória de uns sobre outros fomentou a ideia de superioridade de alguns povos sobre outros, como se certas raças fossem mais dignas de representatividade da espécie humana. Com a modernidade e o desenvolvimento da visão objetiva de mundo, o racismo ganha novos contornos e se torna o modus operandi da política de Estado, na medida em que se esquadrinha a vida e se separam os espaços hierárquicos em que cada forma de existência humana deverá existir.

Aparece nesse momento - o que é um paradoxo em comparação aos próprios fins e à forma primeira desse discurso de que eu lhes falava - um racismo de Estado: um racismo que uma sociedade vai exercer sobre ela mesma, sobre os seus próprios elementos, sobre os seus próprios produtos; um racismo interno, o da purificação permanente, que será uma das dimensões fundamentais da normalização social (Foucault, 1999, p. 73)

Trata-se de uma prática na qual o exercício da soberania não consiste simplesmente em fazer morrer e deixar viver, como se compreenderia no antigo paradigma da soberania, em que o soberano garante a obediência de seus súditos pela ameaça direta à vida, mas de um biopoder que faz viver e deixa morrer, ou seja, que expõe à morte (Foucault, 1999). Para estabelecer o critério de distinção entre esses parâmetros relacionados à decisão soberana sobre quais vidas merecem ser vividas e quais serão expostas à morte, torna-se necessária uma teoria subentendida da raça, um racismo institucionalizado nas práticas e instituições do próprio Estado, ainda que este possua uma narrativa em favor de todos e todas em igualdade.

Esse paradoxo pelo qual um poder ao mesmo tempo investe e destitui a vida de valor, ao qualificá-la ou expô-la à morte, pode ser explicado pelo racismo. "Como esse poder que tem essencialmente o objetivo de fazer viver pode deixar morrer? Como exercer o poder de morte, como exercer a função da morte, num sistema político centrado no biopoder? É aí, creio eu, que intervém o racismo" (Foucault, 1999, p. 304).

Baratta (2002) e Garland (2008) consideram que a biopolítica opera em diferentes contextos políticos, econômicos e institucionais, sendo que a recorrência de discursos oficiais em torno da segurança pública denota a deterioração dos mecanismos legais de contenção da violência urbana. Sem oferecer alternativas econômicas e profissionalizantes condizentes 
para enfrentar o problema nos marcos de uma constituição democrática e socialmente inclusiva, o Estado (seus agentes) pode estabelecer formas de agir diretas e/ou indiretas de matar e/ou terceirizar a morte. Assim, é possível afirmar que, dentre os inúmeros atos de violação dos Direitos Humanos que ocorrem no país, muitos têm relação com a atuação dos aparelhos oficiais de repressão e controle do Estado. Em que pese a importância da constituição vigente, da democracia pluripartidária e de iniciativas governamentais preocupadas em reverter o histórico de desigualdades e exclusão social, a realidade econômica, política e institucional brasileira tem sido caraterizada pela ausência ou fragilidade dos mecanismos institucionais de controle popular sobre as ações do Estado. Segundo Corrêa e Andrade-Souza (2020) há uma micropolítica da insegurança, respaldada no medo como o afeto basal e metabólico que define as sociedades contemporâneas, que ocupa os sujeitos tanto física, quanto mentalmente.

No que se refere ao espaço urbano, a reconfiguração de territórios marcados pela pobreza e estigmatização da comunidade local, pode ser associada ao conceito de marginalidade avançada, em que basta a disseminação de crenças preconceituosas para acarretar consequências extremamente nocivas e justificar a intervenção repressiva e brutal do Estado. Numa circunstância de segregação étnico racial e pobreza, pessoas excluídas do mercado formal de trabalho "são obrigados recorrer a estratégias individuais de auto-aprovisionamento, de trabalho clandestino, de comércio subterrâneo, de atividades criminosas" (Wacquant, 2006, p. 33).Considerando o contexto brasileiro e o processo histórico de colonização, escravização e estigmatização do povo africano, que caracteriza a pobreza e a violência contra a população negra, percebe-se, conforme os dados estatísticos que serão apresentados, que a política de guerra às drogas atinge-os de forma bem mais acentuada.

\section{Política de Drogas, Violência e Superencarceramento}

No Brasil, pressões econômico-políticas neoliberais externas e decisões políticas internas resultam na retração de direitos sociais, expansão do trabalho informal e precário, especulação imobiliária e segregação do espaço urbano, aliado à facilidade de acesso a armas de fogo explicam, ao menos em parte, o fato de muitos jovens pobres e negros estarem mentalmente dispostos a vender sua força de trabalho à indústria de controle do crime. A este respeito, escreve Passetti (2003), enquanto a era da sociedade capitalista industrial fez surgir os exércitos industriais de reserva à espera de uma oportunidade de inserção no mundo legal do trabalho, o capitalismo globalizado e tecnológico fez expandir os exércitos ilegais do narcotráfico, cuja condição pode ser aproveitada como matéria-prima à indústria do controle do crime. Sob este ponto de vista, os presídios brasileiros atestam a expansão do encarceramento no país, cuja relação crime, pobreza e cor da pele assume contornos dramáticos, merecendo destaque, o comercio ilegal de substâncias psicoativas, o qual se aproveita 
[...] da baixa remuneração de uma mão-de-obra de vida útil e restrita, pelos perigos e embates constantes no interior de gangues e com a polícia, quando não com exércitos, mas também computando os custos com corrupção de policiais, militares, juízes e políticos, somados às perdas com a lavagem de dinheiro em bancos legais, os gastos passaram a ser mínimos diante da potencialidade do lucro (Passetti, 2003, p. 276).

Ao analisar os dados estatísticos da violência relacionada a questão das drogas e da sua consequência enquanto política de encarceramento e de extermínio é possível observar a prevalência de um grupo específico de pessoas que são como alvos para o sistema penal, justamente os jovens negros da periferia. Os números representam, de acordo com Zaconne (2007), a seletividade punitiva do sistema de justiça, que acaba por produzir uma cifra oculta da criminalidade.

O estereótipo do bandido vai-se consumando na figura de um jovem negro, funkeiro, morador da favela, próximo do tráfico de drogas vestido com tênis, boné, cordões, portador de algum sinal de orgulho ou de poder e de nenhum sinal de resignação ao desolador cenário de miséria e fome que o circunda (Zaconne, 2007, p. 8).

Seria possível afirmar que desde a abolição formal do regime escravista brasileiro, o Estado tem promovido medidas de branqueamento, e que o mito da democracia racial vem se tornando uma das dificuldades para o debate da violência de Estado principalmente contra a juventude negra. O genocídio no Brasil é silencioso e a dificuldade de comprová-lo se dá justamente por conta da "imposição de uma falsa democracia racial que tem como objetivo a desconstrução dos argumentos que envolvem o racismo, a violência e o genocídio" (Luca, 2017, p. 94).

Contudo, existe uma dificuldade para responsabilização do Estado brasileiro com relação ao racismo e o possível genocídio, pois para isso seria preciso demonstrar a comprovação de ao menos dois elementos: o material, que se comprova através de dados estatísticos e indícios, e o elemento formal, que é ainda mais problemático de demonstrar, pois depende da comprovação da intenção do Estado (policial) brasileiro de cometê-lo. De qualquer forma, alguns números chamam a atenção e precisam ser discutidos, como no caso do aumento exponencial da população carcerária e do crescimento das taxas de letalidade policial nos últimos anos.

Na última década o Brasil simplesmente dobrou o número de pessoas encarceradas, o que não gerou nenhum impacto significativo sobre os índices de violência e tornou o país ○ $3^{\circ}$ maior encarcerador do planeta, atrás apenas de Estados Unidos e China. Segundo - Departamento Levantamento Nacional de Informações Penitenciárias, se em 2005 a quantidade de pessoas presas era de 361,4 mil, em 2016 o Brasil alcançou uma população carcerária de 726.354 mil pessoas, o que representa quase o dobro do número de vagas disponíveis (entre presídios, delegacias e outros) (Brasil, 2017). Isso significa um déficit carcerário de 303.112 mil vagas, ou seja, para que a realidade brasileira pudesse dar conta desse número precisaria mais que dobrar o número de vagas disponíveis nas instituições de 
reclusão. O que também chama a atenção é o número de pessoas privadas de liberdade mesmo sem ter uma condenação, são 292.450 mil pessoas, ou seja, $40 \%$ dos presos brasileiros estão aguardando julgamento. Mais da metade dessa população são jovens de 18 a 29 anos e 64\% das pessoas encarceradas são pretas ou pardas'.

O crescimento da população carcerária segue contínuo, mas parece ter havido um agravamento relacionado ao projeto de lei sobre drogas, promulgada no ano de 2006, que instituiu a política nacional e estabeleceu as normas para repressão à produção não autorizada e ao tráfico ilícito de drogas². Apesar da lei estabelecer a distinção da pena para usuários e traficantes, sendo atenuada e não prevendo encarceramento para quem apenas consome drogas ilícitas, a interpretação da aplicação da lei, no que se refere ao enquadramento por tráfico ou não, cabe a figura do juiz, conforme se observa pelo artigo 28 da Lei $11.343^{3}$. O que se observa, portanto, é que a falta de critério para distinguir entre usuários e traficantes contribuiu significativamente para aumentar exponencialmente o número de pessoas presas nos últimos anos. Segundo o próprio Infopen, em 2006 tínhamos 47 mil presos por crimes de drogas (14\% do total). Em 2013 passaram a 138 mil (1 em cada 4 presos), já em 2016 o número alcançou o total de 156.749 mil pessoas (Brasil, 2017).

Além da superlotação dos presídios e o dinheiro gasto para manter a estrutura de encarceramento e repressão, é necessário considerar todo investimento gasto em segurança pública e na indústria de controle sobre o crime, que poderia ser utilizado na qualificação de serviços básicos essenciais de assistência social, saúde e educação. Diante do déficit relacionado a esse tipo de investimento, não é por acaso que os índices de violência no Brasil estão entre os 10 mais altos do mundo, chegando a quase 31,6 por 100 mil habitantes, de acordo com o Atlas da Violência (IPEA, 2019). Em 2017, por exemplo, somaram-se 65.602 mil homicídios, sendo a maior parte jovens. Considerando a população jovem em geral houve um aumento de 6,7\% com relação a 2016 e de 37,5\% em relação a 2007.

Entre 2007 e 2017 houve um crescimento de homicídios de pessoas negras em 33,1\%, uma proporção bem maior do que o aumento de 3,3\% entre a população branca. Os dados mais recentes sobre a "Violência em números no Brasil" mostram que as pessoas do sexo masculino perfazem a cifra de $99,3 \%$ dos casos, $77,9 \%$ entre 15 e 29 anos e $75,4 \%$ negros, sendo que 11 a cada 100 mortes violentas intencionais foram provocadas pelas polícias, onde 17 pessoas foram mortas por dia, gerando um total de 6.220 vítimas em 2018 (IPEA, 2019). Considerando o seletividade etnico-racial, observa-se claramente o perfil da população exterminada, porém, se for considerado o número de policiais mortos, também se nota um cenário mais grave para a populaçao negra, onde $97 \%$ são homens, $51,7 \%$ negros e 65,5\% tinham entre 30 e 49 anos. Neste contexto há uma preocupação acentuada em relação à proteção da população, mas também um agravante em relação à saúde mental dos agentes, onde mais policiais foram vítimas de suicídio do que assassinados no horário de trabalho, sendo 104 suicídios naquele ano. 
Fatores como a distribuição de pessoas negras nos estados e a quantidade populacional certamente podem interferir na análise, considerando que o Brasil é um país de imensa área geográfica e desigualdades socioeconômicas entre as regiões, mas seria ideal que houvesse dados detalhados sobre os crimes de drogas, para poder verificar a fonte de violência contra a juventude negra presente em cada região, além das situações que envolvem as mortes decorrentes de intervenção policial. Segundo o Instituto Brasileiro de Estatística Aplicada (IPEA, 2019), as maiores taxas de homicídios de negros encontram-se nos estados de Sergipe $(79,0 \%)$ e do Rio Grande do Norte (70,5\%). Na década 2006-2016, esses estados foram os que também apresentaram as maiores taxas: $172,3 \%$ e $321,1 \%$, respectivamente. Já as menores taxas de homicídios de negros foram encontradas nos estados de São Paulo (13,5\%), do Paraná $(19,0 \%)$ e de Santa Catarina $(22,4 \%)$. São Paulo, que é o estado com maior número de crimes de tráfico de drogas é também o segundo estado a mais vitimizar policiais e, ainda, o estado com maior ocorrência de mortes decorrentes de intervenção policial, seguidos de Rio de Janeiro e Paraná.

O Fórum de Segurança Pública analisou 573 boletins de ocorrência de policiais vítimas de homicídio, o que representa $70,8 \%$ do universo dessas mortes nesse período e o Anuário Brasileiro de Segurança Pública de 2017 é o primeiro no qual esses dados referentes ao perfil racial de policiais mortos são divulgados, não possibilitando uma análise da série histórica. Com a impossibilidade de negar o viés racial da violência no Brasil, Cerqueira e Coelho (2017) mostraram que há determinantes da probabilidade de sofrer homicídios na cidade do Rio de Janeiro, onde indivíduos negros possuem $23,5 \%$ mais chances de serem vítimas e que, aos 21 anos de idade, quando há o pico das chances de ser vítima de homicídio, os indivíduos negros possuem $147 \%$ mais chances de serem assassinados.

Segundo o IPEA (2019) a taxa de homicídios por 100 mil negros no Brasil em 2017, foi de 43,1, e a taxa de não negros (brancos, amarelos e indígenas) foi de 16,0. Ou seja, proporcionalmente às respectivas populações, para cada indivíduo não negro que sofreu homicídio, aproximadamente, 2,7 negros foram mortos. 


\section{Quadro 1. Dados de homicídio entre negros e não negros e população total em 2017, por região no Brasil.}

\begin{tabular}{|c|c|c|c|c|}
\hline $\begin{array}{l}\text { REGIÕES } \\
\text { Estados }\end{array}$ & $\begin{array}{l}\text { Número de homicí- } \\
\text { dios negros }\end{array}$ & $\begin{array}{l}\text { Total popula- } \\
\text { ção negra }\end{array}$ & $\begin{array}{c}\text { Número homicídios } \\
\text { não negros }\end{array}$ & $\begin{array}{c}\text { Total } \\
\text { população não ne- } \\
\text { gra }\end{array}$ \\
\hline \multicolumn{5}{|l|}{ REGIĀO NORTE } \\
\hline Acre & 428 & 652.875 & 77 & 163.588 \\
\hline Amapá & 351 & 635.492 & 24 & 156.296 \\
\hline Amazonas & 1.516 & 3.115 .326 & 146 & 802.849 \\
\hline Pará & 4.144 & 6.714 .678 & 329 & 1.613 .593 \\
\hline Rondônia & 397 & 1.225 .081 & 145 & 571.681 \\
\hline Roraima & 185 & 337.260 & 61 & 128.761 \\
\hline Tocantins & 437 & 1.158 .134 & 103 & 379.745 \\
\hline \multicolumn{5}{|l|}{ REGIĀO CENTRO-OESTE } \\
\hline Distrito Federal & 486 & 1.871 .695 & 121 & 1.162 .461 \\
\hline Goiás & 2.284 & 4.310 .972 & 561 & 2.466 .079 \\
\hline Mato Grosso & 850 & 2.210 .470 & 244 & 1.086 .004 \\
\hline Mato Grosso do Sul & 418 & 1.469 .485 & 237 & 1.178 .156 \\
\hline \multicolumn{5}{|l|}{ REGIÃO NORDESTE } \\
\hline Alagoas & 1.740 & 2.562 .698 & 30 & 806.485 \\
\hline Bahia & 6.798 & 12.286 .364 & 484 & 3.037 .477 \\
\hline Ceará & 4.905 & 6.484 .298 & 323 & 2.537 .172 \\
\hline Maranhão & 1.968 & 5.630 .496 & 181 & 1.334 .209 \\
\hline Paraíba & 1.227 & 2.644 .454 & 96 & 1.358 .304 \\
\hline Pernambuco & 4.720 & 6.450 .047 & 630 & 2.963 .320 \\
\hline Piauí & 549 & 2.557 .141 & 55 & 662.812 \\
\hline Rio Grande do Norte & 1.928 & 2.215 .177 & 195 & 1.291 .863 \\
\hline Sergipe & 1.232 & 1.790 .593 & 79 & 497.570 \\
\hline \multicolumn{5}{|l|}{ REGIĀO SUDESTE } \\
\hline Espírito Santo & 1.214 & 2.416 .383 & 187 & 1.595 .908 \\
\hline Minas Gerais & 3.146 & 12.518 .839 & 1.096 & 8.591 .544 \\
\hline São Paulo & 2.168 & 17.179 .750 & $2.415^{*}$ & 27.915 .500 \\
\hline Rio de Janeiro & 4.650 & 9.314 .098 & 1.634 & 7.406 .601 \\
\hline \multicolumn{5}{|l|}{ REGIÃO SUL } \\
\hline Paraná & 680 & 3.581 .742 & 2.045 & 7.728 .111 \\
\hline Santa Catarina & 270 & 1.179 .981 & 787 & 5.807 .643 \\
\hline Rio Grande do Sul & 833 & 2.267 .001 & 2.449 & 9.043 .084 \\
\hline BRASIL & 49.524 & 114.780 .529 & 14.734 & 92.286 .815 \\
\hline
\end{tabular}

Fonte: IPEA, 2019. Origem dos dados IBGE - Pesquisa Nacional por Amostra de Domicílios e Sistema de Informações sobre Mortalidade do Ministério da Saúde, Brasil, 2017.

* estados com maior número de homicídios de população não negra. 
Os dados do quadro 1 revelam a profunda desigualdade racial no país, ainda que esse processo se manifeste de formas distintas em cenários estaduais e regionais. Há de salientar que no estado de São Paulo, Santa Catarina, Paraná e Rio Grande do Sul, em números absolutos, apresentam uma ordem inversa com relação aos demais Estados, sendo a morte da população não negra maior que da população negra, isso porque nesses Estados a população negra é a minoria local. O caso de Alagoas, por exemplo, é emblemático, pois demonstra o tamanho da desigualdade racial existente no país, ao apresentar a diferença mais acentuada de todas as unidades da Federação, sendo 18,3 vezes maior o homicídio de pessoas negras do que não negras.

Cabe salientar também que há diferenças entre os dados provenientes do sistema da saúde nacional, que alimentam o Atlas da Violência (2019) e do sistema de segurança nacional fornecidos pelos registros da polícia, que indicam queda no número de ocorrências policiais envolvendo homicídios. Há exemplos de Estado da região Norte no qual existem 403 vítimas a menos, e na região nordeste com 572 vítimas a menos registrados no sistema policial. Isso alerta para o necessário e contínuo investimento em monitoramento, avaliação e auditoria da qualidade dos dados no Brasil.

Com relação aos dados do sistema de medida socioeducativa levantados pelo Sinase (2019), pode ser observado que o jovem em conflito com a lei também é em sua maioria negro. Em 2017, dos 143.000 adolescentes em meio aberto e fechado, 56\% são negros, em sua maioria presos por crimes relacionados a roubo (44\%) ou tráfico de drogas (24\%). No período entre 2012 e 2017 observa-se um aumento do número relativo ao crime de tráfico, posse e uso de entorpecentes, que no total somaram 299.252 casos. Com relação ao universo feminino a relação entre lei de drogas, racismo e encarceramento se torna mais perceptível. Embora as mulheres jovens em cumprimento de medida socioeducativa representem apenas 3,8\% do total, $62 \%$ são negras. Dos 628 atos infracionais praticados, 163 tem relação com tráfico de entorpecentes, ou seja, 38,8\% do total, sendo que o roubo cai para 15,2\%. No período entre 2000 e 2016, a taxa de encarceramento de mulheres aumentou 545\% no Brasil, passando de 6,5 mulheres a cada 100 mil habitantes para 40,6 mulheres encarceradas em cada grupo de 100 mil (Brasil, 2019).

Em relação a faixa etária das pessoas privadas de liberdade no Brasil, é possível constatar que a maior parte é composta por jovens, segundo o Levantamento nacional de informações penitenciárias (Brasil, 2019). Entre estes, quase 30\% possuem entre 18 a 24 anos, seguido de $24,1 \%$ entre 25 a 29 anos e 19,4\% entre 35 a 45 anos. Somados o total de presos até 29 anos de idade totalizam $54 \%$ da população carcerária. O total da população privada de liberdade no Brasil em 2017 era de 726.354 com um total de vagas de 423.242, sendo que a taxa de ocupação corresponde a mais de $170 \%$. Os dados indicam que a população negra representa 55,4\% da população brasileira, um índice bastante discrepante se comparado com o índice da população branca que se encontra encarcerada, conforme demonstra gráfico 1. 


\section{Gráfico 1. Percentual de etnias de brasileiros e de etnias de brasileiros no sistema prisional. Brasil, 2017.}

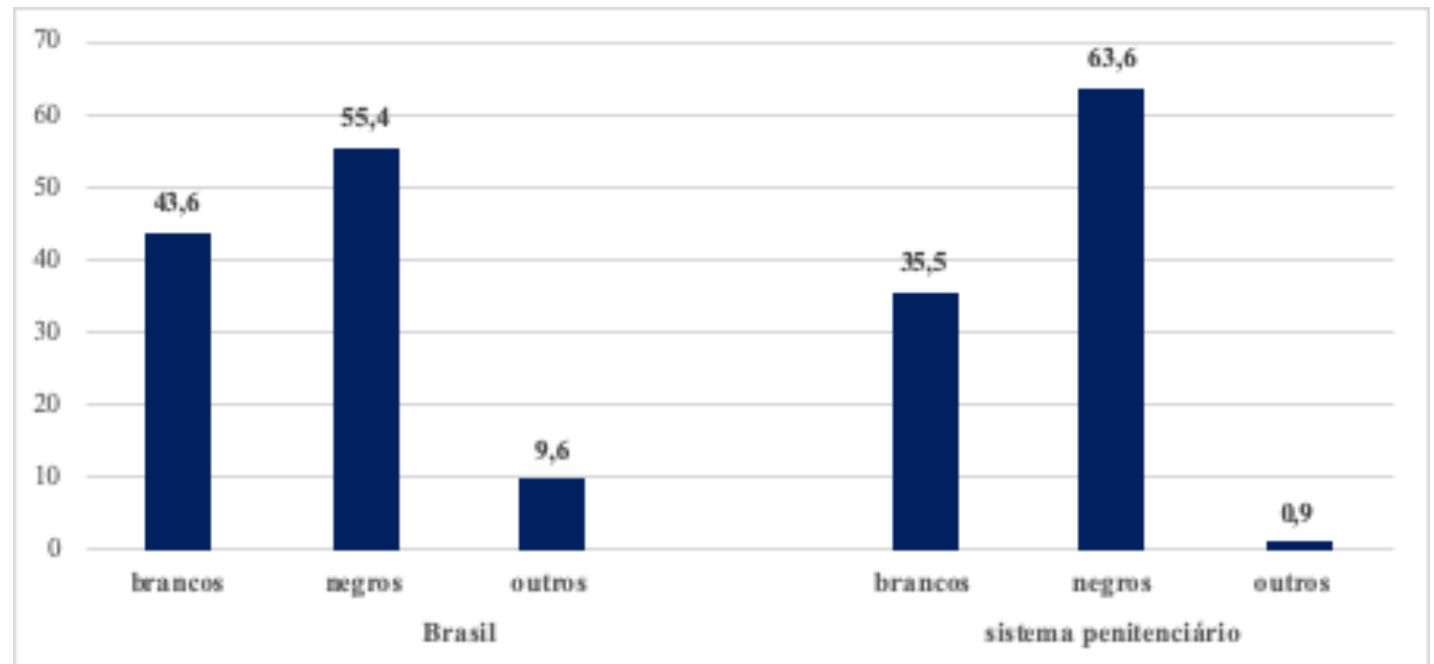

Fonte: Levantamento Nacional de Informaçōes Penitenciárias - Infopen, Junho/2017.

O contexto das instituições de privação de liberdade para jovens no Brasil é constantemente reafirmado como um local de violência, desigualdade e incapacidade de garantia de direitos, o que exige compromissos éticos na elaboração e implementação de políticas públicas (Garay-Hernandez et al., 2018). Considerando os índices de letalidade policial, 21.910 pessoas morreram em decorrência de intervenções policiais no Brasil entre os anos de 2009 e 2016, posicionando o país entre as forças policiais mais letais do planeta, causando efeitos nocivos sobre as instituições e da própria democracia. A disseminação das armas de fogo e a não observância legal de muitas circunstâncias ligadas à atuação da polícia, tendem alimentar a cultura do extermínio no país (Zilli, 2018). A morte está "entre determinados segmentos das organizações policiais e profissionais de segurança pública, mas também em um conjunto de crenças e valores professado por parte expressiva da sociedade civil que suporta e, não raramente, incentiva práticas de violência policial" (Zili, 2018, p. 78-79).

Para Sinhoretto e Morais (2017), nos anos recentes, o viés racial na configuração de mortes violentas no Brasil se evidenciou, indicando na população jovem, o crescimento de homicídios entre negros e a redução entre brancos, o que significa o crescimento da desigualdade na vivência da violência entre os grupos raciais. Dentro deste cenário os autores demonstram que a população encarcerada cresceu, impulsionada pelo encarceramento de jovens negros. O Mapa do Encarceramento - os jovens do Brasil (Brasil, 2015), discute que aos negros são aplicadas penas mais severas comparativamente aos brancos historicamente, demonstrando a desigualdade racial do campo da justiça criminal no país. 


\section{"Guerra às drogas" e racismo}

Como foi observado, esse cenário de repressão estatal ao crime de tráfico de drogas torna a polícia brasileira uma das que mais mata no mundo, como também está entre a que mais morre, pelo gerenciamento violento e repressivo da desigualdade e da exclusão, tendo como foco o combate às drogas. Em última instância, trata-se de cidadãos pobres matando outros cidadãos pobres, numa espécie de jogo de poder entre os soldados do Estado e os soldados do tráfico, em que ninguém sai vencedor. Cabe ressaltar também que, enquanto o número de policiais mortos em confronto tende a ser preciso, as estatísticas referentes a pessoas mortas pela polícia devem estar subestimadas, uma vez que existem casos que não são descobertos ou relatados.

Contudo, é necessário considerar os limites com relação a forma que se produzem tais dados no Brasil, não apenas no que se refere a subnotificação e a ausência do recorte étnico racial em algumas estatísticas, como no caso do crime de tráfico de drogas, mas também como a questão étnico-racial aparece nesses relatórios. No caso do encarceramento, por exemplo, não existem dados sobre crimes relacionados às drogas com a classificação étnico-racial, o que parece ser proposital para ocultar a relação direta entre a lei de drogas e o racismo. Por outro lado, a categoria 'negro' é sempre reforçada como sendo a maior parte da população carcerária, o que pode contribuir para a estigmatização histórica relacionada a crença de que as pessoas de determinadas etnias podem ser mais violentas e propensas ao crime do que outras, naturalizando o racismo. Essa tendência de criminalizar as pessoas negras por supostos traços biológicos que explicariam os altos índices estatísticos, já havia sido levantada por Lombroso (1877) e desenvolvida por Nina Rodrigues (1957) no Brasil, o que torna necessário um olhar crítico sobre a criminologia em seu processo de produção de dados sobre a população negra, para não cair no racismo biológico. Do mesmo modo que a criminologia crítica supõe uma virada criminológica, seria necessária uma virada racial, para que a temática racial e a categoria negro seja incorporada não apenas como objeto de pesquisa, mas também em uma perspectiva metodológica e epistemológica (Ortegal, 2016).

De qualquer forma a proibição das drogas "tem sido o fator central da expansão do poder punitivo e, consequentemente, da crescente criminalização da pobreza, globalmente registrada desde as últimas décadas do passado século XX" (Karam, 2013, p. 35). Do ponto de vista biopolítico, trata-se de um processo de controle sobre os hábitos da população que atinge principalmente os mais pobres, na medida em que são os moradores das favelas que pagam o preço mais alto por estarem sobre fogo cruzado. Tudo isso se justificaria em função de uma perspectiva excessivamente mistificadora com relação ao poder da droga em gerar dependência química e destruição do usuário, ignorando os problemas sociais na análise do problema. A política de drogas se desenvolve "a partir de um imbróglio de discursos que se anulam e se complementam, aludindo-iludindo, apoiados fundamentalmente em uma fantasmagoria a-científica, (onde as drogas são a encarnação do 'mal')"' (Costa, 2017, p. 31). 
Parece óbvio que muitas vidas são destruídas pelo uso abusivo de drogas, porém o que se define como política pública para evitar que isso aconteça pode ser ainda pior, principalmente para a população negra e pobre. Cabe ressaltar que a chamada "dependência química" não se desenvolve exclusivamente em função do efeito da droga, mas por uma série de outros sofrimentos que são ocultados pelo foco no poder da substância, tornando-a bode expiatório de grande parte das mazelas sociais.

De acordo com as pesquisas do neurocientista norte-americano Hart (2014), especialista no estudo sobre drogas e dependência, o que se acredita saber sobre as drogas, inclusive sobre o crack, a heroína e a cocaína, se baseia muito mais em mitos e preconceitos, do que em evidências científicas. A porcentagem de usuários de drogas que realmente se viciam, considerando a definição de vício ligada ao comprometimento de funções vitais relacionadas ao trabalho, estudo ou relações interpessoais é muito menor do que se acredita. De acordo com Hart (2014, p. 23) "as pesquisas demonstram reiteradamente que essas questões afetam apenas entre 10 e $25 \%$ daqueles que experimentam até as drogas mais estigmatizadas, como heroína e crack".

A gravidade da dependência química está relacionada não à substância em si, mas principalmente à quantidade de opções que uma pessoa tem, no sentido de poder fazer escolhas diferentes. Dessa forma, se alguém tiver outras oportunidades além do uso da substância ela terá grandes chances de realizar escolhas alternativas. Os resultados apontam que o uso de drogas em espaços controlados contraria a tese do "senso comum segundo o qual o comportamento viciado seria completamente irascível" (Hart, 2014, p. 260). Mesmo contra as evidências cientificas, a visão da sociedade sobre as drogas permanece inalterada, sempre atribuindo a ela a responsabilidade pela violência e criminalidade.

Trata-se de algo que parece não ser por acaso ou apenas fruto da ignorância de uma sociedade mal informada, mas que se caracteriza como mais um elemento estratégico de dominação biopolítica. Tornar o crack o bode expiatório dos problemas da sociedade e o responsável por levar alguém a viver na rua possuem caráter claramente biopolíticos de dominação ideológica e controle sobre os corpos, na medida em que se vende a ideia de que há necessidade de construção de mais prisões e de imposição de sentenças mais pesadas. O que se pretende esconder da população é o fato, evidenciado por Hart (2014, p. 261), de que "as diferenças na prevalência dos problemas relacionados ao crack decorrem sobretudo das oportunidades econômicas, e não de propriedades particulares da droga". Tal evidência favorece a compreensão do porquê da visão sobre as drogas continuar superficial e pouco complexa, alimentando a indústria da segurança pública, a lógica da punição e o próprio racismo. 
O pior é que o crack foi absorto em uma narrativa de raça e patologia. Enquanto a cocaína em pó chegou a ser considerada um símbolo de luxo e associada aos brancos, o crack foi retratado como causador de efeitos exclusivamente viciantes, imprevisíveis e mortais e foi, essencialmente, associado aos negros. É claro que, por volta da década de 1980, as referências à raça em tal contexto já não eram aceitáveis. Então, os problemas relacionados ao crack foram descritos como sendo prevalentes nos bairros pobres, urbanos ou problemáticos, bolsões de pobreza e guetos, termos que foram usados como códigos para fazer referência aos negros e outras pessoas indesejadas (Hart, 2015, p. 2).

Embora Hart esteja fazendo referência a realidade do Estados Unidos, em suas visitas ao Brasil o professor da Universidade de Columbia percebeu que a mesma lógica que predominou a dez anos atrás em seu país, agora toma conta da política sobre drogas no Brasil. Em seu artigo Slogans vazios, problemas reais o autor fala sobre uma experiência pessoal no trânsito do Rio de janeiro, quando ele vê o adesivo em um carro com a frase: 'crack, é possível vencer'. Trata-se do tipo de informação que "são excelentes para animar os desinformados, mas eles também frequentemente escondem os verdadeiros problemas e obstruem nossa capacidade de implementar soluções adequadas" (Hart, 2015, p. 4).

Entretanto, se a falência desse modelo se revela de forma bastante óbvia, quais devem ser as motivações dessa insistência por parte do poder público? Se mesmo após algumas décadas de investimentos massivo nas campanhas proibicionistas e na indústria de controle sobre o tráfico de drogas o acesso a elas é cada vez mais fácil, bem como a quantidade de pessoa presas sobe exponencialmente, que forças e interesses ocultos justificam a lógica proibicionista e beligerante? Estariam os governantes apenas preocupados com a saúde da população e a possibilidade de acesso a droga por crianças e jovens, ou talvez existam interesses escusos de natureza autoritária na política de 'guerra às drogas', inclusive o próprio racismo de estado?

Nesse caso, a política sobre drogas no Brasil está relacionada não apenas a um determinado modo biopolítico de fazer viver, mas também com práticas autoritárias de gestão do poder e de questões sociais que fomentam a desigualdade e a exclusão, as quais inevitavelmente incidem em decisões políticas e determinações institucionais que expõem à morte ou, até mesmo, em práticas de extermínio da população, em sua maioria jovens negros e pobres. Trata-se de uma forma de exercício do poder soberano onde a morte é um fator determinante para a manutenção do poder e a escolha biopolítica entre quem deve viver e quem deve ser deixado para morrer ou ser morto. Trata-se, na verdade, de uma biopolítica sobre drogas que se revela como necropolítica, na qual "padecem os corpos negros sob as formas novas e únicas de existência social, nas quais vastas populações são submetidas a condições de vida que lhes conferem o status de "mortos-vivos" (Mbembe, 2016, p. 146).

Ainda que aspectos de biopolítica sejam evidentes no mundo colonizado, Mbembe (2016) evidencia que, nesses territórios, tais práticas foram essencialmente de proporcionar a morte, ou seja, de fazer morrer como forma de dominação da vida, por isso uma 
necropolítica. Matar nas colônias estava fora de qualquer ilegalidade, uma vez que os povos escravizados não possuíam critérios de humanidade definidos na racionalidade do mundo europeu. "Aos olhos do conquistador, 'vida selvagem' é apenas outra forma de 'vida animal', uma experiência assustadora, algo alienígena além da imaginação ou compreensão" (Mbembe, 2016, p. 133).

Nesse sentido, o processo colonial brasileiro continua em curso, não mais por meio de um processo de escravização legalmente autorizado, como era no passado, mas tendo por base uma biopolítica sobre drogas, a qual tem na substância o alvo a ser combatido. Entretanto, quem acaba sendo atingido é a população negra, especialmente jovem, quer seja pelo envolvimento com o tráfico de drogas ou pelo simples fato de estar no lugar errado e na hora errada. Diante desse cenário, o movimento negro e as organizações de direitos humanos no Brasil têm se mobilizado no sentido de denunciar esse genocídio associado à política de drogas e defendido a descriminalização como um ponto fundamental da superação do problema. É o caso, por exemplo, da construção da Iniciativa Negra Por Uma Nova Política sobre Drogas (INNPD), a qual surge como uma forma de realizar esse enfrentamento.

Ao longo dos últimos três anos, a INNPD tem se consolidado como uma importante experiência negra de advocacy no campo da política de drogas, organizando pesquisas, dados, seminários, fóruns e produtos de comunicação a partir de conexões produzidas entre a política conhecida como "guerra às drogas" e as relações raciais no Brasil, com o intuito de produzir tecnologias de formação e imprimir ações políticas no campo da política sobre drogas, com especial atenção aos temas relacionados a encarceramento, Sistema de Justiça e segurança pública (Oliveira e Ribeiro, 2018, p. 40).

Iniciativas dessa natureza tornam-se vitais para a transformação do quadro generalizado de violência contra a população negra periférica no Brasil, induzida pela política de drogas. Urge a necessidade de repensar a forma como a sociedade lida com o problema do uso abusivo de drogas, visto que a estratégia de atuação do Estado brasileiro está comprometida com o racismo e com o número absurdo de jovens mortos.

\section{Considerações finais}

No decorrer do estudo foi possível perceber que nos últimos anos, mesmo com maior investimento governamental em segurança pública, houve um aumento expressivo dos homicídios, na prática de encarceramento e nos índices relativos ao crime de tráfico de drogas e associação ao tráfico, o que atinge especialmente a população negra. Assim como o indivíduo utiliza de defesas psíquicas para justificar e mascarar seus comportamentos racistas culpabilizando as pessoas vítimas da opressão racial pelos próprios atos, o Estado, através de uma política de drogas racista, acaba por justificar essas ações através do proibicionismo e da criminalização. 
A caracterização racial aparece nos dados de mortes decorrentes de intervenções policiais e em dados de vitimização policial e o que estes trazem é que tanto os suspeitos mortos pela polícia quanto os policiais mortos são em sua maioria negros, o que vai de acordo as reflexões de autores como Foucault (1999), Wacquant (2006), Hart $(2014,2015)$ e Mbembe (2016), acerca do caráter racista e classista do Estado na esfera de controle do crime nas sociedades contemporâneas. Não é somente através da morte direta, como os assassinatos cometidos pela polícia, que o Estado exerce o poder de matar. O fato de jovens negros e policiais negros aparecerem como as maiores vítimas de assassinato no Brasil evidencia a multiplicação do risco representa um projeto não apenas biopolítico, mas necropolítico, uma vez que não apenas expõe a morte, mas a produz.

O problema pode ser ainda maior do que os dados revelam, pois, o número de mortes decorrentes de intervenção policial, assim como os dados de vitimização policial possuem um grande percentual de casos em que não foi informada a identificação racial das vítimas, o que é sintomático com relação a naturalização do racismo. Muitas vezes, falar de racismo no Brasil é, justamente, falar também sobre o que não é dito sobre a morte de pessoas negras.

Desse modo, investir no modelo atual que parece funcionar seletivamente à base da criminalização-prisão representa, por certo, uma forma de gastar muito dinheiro público sem inverter a lógica histórica de intervenção estatal que contribui para aumentar o abismo entre brancos e negros no Brasil. Urge a necessidade de uma reforma nas medidas de punição de crimes cometidos sem violência, especialmente sobre o crime de tráfico, pois este é um crime econômico e a solução passa por maiores oportunidades econômicas e inciativas político-jurídicas de descriminalização das substâncias psicoativas.

\section{Notas}

1 Apesar da falta de consenso com relação a aproximação ou distanciamento entre pretos e pardos na análise das classificações e estatísticas populacionais, neste artigo assumimos a potencial proximidade entre esses grupos, considerando a similaridade com relação aos padrões de vulnerabilidade, embora o racismo aumente na medida em que tom da pele for mais escuro. Desse modo, seguimos a linha dos pesquisadores que consideram que mesmo existindo diferenças consideráveis entre pretos e pardos, a distância destes para os brancos é muito mais profunda, o que justificaria a aproximação entre os grupos na investigação social, visto que pretos e pardos padecem do mesmo tipo de discriminação e exclusão. (Silva, Hasenbalg e Lima, 1999; Munanga, 1999; Sheriff, 2003). Com isso, pretendemos ir contra o mito da democracia racial no Brasil, considerando que no Brasil existe um conflito generalizado que procurou ser encoberto pela lógica da mestiçagem. Segundo Bernardino (2002, p. 250), "o mito da democracia racial apoiava-se, e ainda se apoia, na generalização de casos de ascensão social do mulato; este, nas palavras de Carl Degler, encontrara uma "saída de emergência", o que significa dizer que se desenvolveu um reconhecimento social do mestiço no Brasil". 
${ }^{2}$ Trata-se da Lei Federal no 11.343, de 23 de agosto de 2006, a qual: "institui o Sistema Nacional de Políticas Públicas sobre Drogas - Sisnad; prescreve medidas para prevenção do uso indevido, atenção e reinserção social de usuários e dependentes de drogas; estabelece normas para repressão à produção não autorizada e ao tráfico ilícito de drogas; define crimes e dá outras providências" (Brasil, 2006).

${ }^{3} \mathrm{O}$ artigo 28 prevê que o enquadramento da lei para quem "adquirir, guardar, tiver em depósito, transportar ou trouxer consigo, para consumo pessoal, drogas sem autorização ou em desacordo com determinação legal, cabe a autoridade do juiz avaliar conforme à natureza e à quantidade da substância apreendida, ao local e às condições em que se desenvolveu a ação, às circunstâncias sociais e pessoais, bem como à conduta e aos antecedentes do agente (Brasil, 2006).

\section{Bibliografia}

Baratta, A. (2002). Criminologia crítica e crítica do direito penal: introdução à sociologia do direito penal. 3. ed. Rio de Janeiro, Brasil: Revan.

Brasil. Lei no 1 1.343, de 23 de agosto de 2006. Institui o Sistema Nacional de Políticas Públicas sobre Drogas - Sisnad; prescreve medidas para prevenção do uso indevido, atenção e reinserção social de usuários e dependentes de drogas; estabelece normas para repressão à produção não autorizada e ao tráfico ilícito de drogas; define crimes e dá outras providências. (2006). Recuperado de http://www.planalto.gov.br/ccivil_03/_Ato2004-2006/2006/Lei/L1 1343.htm . Ministério da Justiça e Segurança Pública. (2017). Levantamento nacional de informações penitenciárias. Brasília, Brasil: MJSP. . Ministério da Mulher, da Família e dos Direitos Humanos (MMFDH). Levantamento anual Sinase 2017. Brasília: Ministério da Mulher, da Família e dos Direitos Humanos, 2019.

Bernardino, J. (2002). Ação afirmativa e a rediscussão do mito da democracia racial no Brasil. Estudos Afro-Asiáticos, 24 (2), 247-273. Doi: 10.1590/S0101$546 \times 2002000200002$.

Cerqueira, D., \& Coelho D. S. C. (2017). Democracia racial e homicídios de jovens negros na cidade partida. Brasília, Brasil: IPEA.

Costa, A. S. (2007). A regra da exceção: poder soberano e biopolítica na "guerra às drogas" no Brasil. Niterói, Brasil: Universidade Federal Fluminense.

Corrêa, M. D. C, \& Andrade-Souza, K.C. (2020). Afetar o por vir dos corpos: micropolíticas da insegurança neoliberal. Polis (Santiago), 19(55), 8-31. Doi: 10.32735/s0718-6568/2020-n55-1441

Fórum Brasileiro de Segurança Pública. Anuário Brasileiro de Segurança Pública 2017. (2017). São Paulo, Brasil: OSF.

Foucault, M. (1988). História da sexualidade I: a vontade do saber. Rio de Janeiro, Brasil: Graal.

- (1996). A ordem do discurso: aula inaugural no Collège de France, pronunciada em 2 de dezembro de 1970. São Paulo, Brasil: Loyola. . (1999). Em defesa da sociedade. São Paulo, Brasil: Martins Fontes.

Garay-Hernandez, J.; Uziel, A.P.; Nascimento, M.A.F.; \& Alves Pinho, G.S. (2018). Sentidos e práticas de paternidade: vozes de homens jovens em privação de liberdade. Polis, 17(50), 69-90. Doi: 10.4067/S0718-65682018000200069.

Garland, D. (2008). A cultura do controle: crime e ordem social na sociedade contemporânea. Rio de Janeiro, Brasil: Revan.

Hart, C. (2014). Um preço muito alto: a jornada de um neurocientista que desafia a nossa visão sobre as drogas. Rio de Janeiro, Brasil: Zahar.

Hart, C. (2015). Slogans vazios, problemas reais. Revista Sur, 21, 1-5. Recuperado de https://sur.conectas.org/wp-content/uploads/2015/09/Sur-21_completo_ pt.pdf 
Hasenbalg, C. (1996), "Entre o Mito e os Fatos: Racismo e Relações Raciais no Brasil", En: M. C. Maio; R. V. Santos (eds.), Raça, Ciência e Soçiedade. Rio de Janeiro, Fiocruz/CCBB, pp. 235-249.

Instituto de Pesquisa Estatística Aplicada - IPEA. Atlas da violência 2018. (2018). Rio de Janeiro, Brasil: IPEA. Recuperado de http://www.ipea.gov.br/portal/images/stories/PDFs/relatorio_institucional/180604_atlas_da_violencia_2018.pdf.

Instituto de Pesquisa Estatística Aplicada - IPEA. Âtlas da violência 2019. (2019). Rio de Janeiro: IPEA. Recuperado de http://www.ipea.gov.br/atlasviolencia/ download/19/atlas-da-violencia-2019.

Karam, M.L. (2013). Direitos humanos, laço social e drogas: por uma política solidária com o sofrimento humano - Em drogas, direitos humanos e laço social. Brasília, Brasil: Conselho Federal de Psicologia.

Lombroso, C. (1887). L'Homme Criminel. Paris, France: Félix Alcan.

Luca, N. M. (2017). A carne mais barata do mercado: uma análise da violência do estado, o extermínio da juventude negra e a possibilidade de enquadramento de crime de genocídio perante o ordenamento internacional (Dissertação de Mestrado). Pontifícia Universidade Católica do Paraná, Curitiba, Brasil

Mbembe, A. (2016). Necropolítica. Arte \& Ensaios, 32, 122-151. Recuperado de https://revistas.ufrj.br/index.php/ae/article/view/8993/7169

Munanga, K. (1999). Rediscutindo a Mestiçagem no Brasil: Identidade Nacional versus Identidade Negra. Petrópolis, Brasil, Vozes.

Rodrigues, R. N. (1957). As Raças Humanas e a Responsabilidade Penal no Brasil. Salvador, Brasil: Livraria Progresso.

Oliveira, N., \& Ribeiro, E. (2018). O massacre negro brasileiro na guerra às drogas. Revista Sur, 15, 35-43. Recuperado de https://sur.conectas.org/o-massacre-negro-brasileiro-na-guerra-as-drogas/

Ortegal, L. (2016). Raça, criminologia e sociologia da violência: contribuições a um debate necessário. Cadernos do CEAS, 238, 527-542. Doi: 10.25247/2447$861 \times .2016 . n 238 . p 527-542$

Passetti, E. (2003). Anarquismos e sociedade de controle. São Paulo, Brasil: Cortez.

Quintana, L. (2012). Singularización política (Arendt) o subjetivación ética (Foucault): dos formas de interrupción frente a la administración de la vida. Revista de Estudios Sociales, 43, 50-62.

Sheriff, R. (2003). "Embracing Race: Deconstructing Mestiçagem". The Journal of Latin American Anthropology, 08, 86-1 15. Doi: 10.1525/jlca.2003.8.1.86

Sinhoretto, J., \& Morais, D. S. (2018). Violência e racismo: novas faces de uma afinidade reiterada. Revista de Estudios Sociales, 64, 15-26. Doi: 10.7440/ res64.2018.02

Wacquant, L. (2006). A estigmatização territorial na cidade da marginalidade avançada. Revista da Faculdade de Letras da Universidade do Porto, 16, 27-39.

Zaconne, O. (2007). Acionistas do nada: quem são os traficantes de drogas. Rio de Janeiro, Brasil: Revan.

Zilli, L.F. (2018). Letalidade e vitimização policial: características gerais do fenômeno em três estados brasileiros. Boletim de Análise Político-Institucional, 17, 7180. Recuperado de http://repositorio.ipea.gov.br/bitstream/1 1058/8873/1/ bapi_17_cap_10.pdf

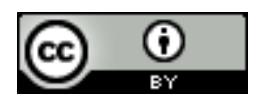

Este es un artículo de acceso abierto bajo licencia Creative Commons Reconocimiento 4.0 Internacional 